\title{
Destructive properties of formalin on human otoconia
}

Rüdiger Kniep ${ }^{1 \dagger}$, Jana Buder $^{1 \dagger}$, Alexander Blödow $^{2}$ and Leif Erik Walther ${ }^{3^{*}}$

*Correspondence: Leif Erik Walther@hno-praxis.sulzbach.de

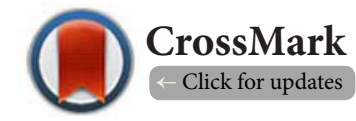

${ }^{t}$ These authors contributed equally to this work.

${ }^{1}$ Max-Planck-Institute for Chemical Physics of Solids, Nöthnitzer Straße 40, D-01187 Dresden, Germany.

${ }^{2}$ Department of Otorhinolaryngology, Helios Clinic Berlin-Buch, Schwanebecker Chaussee 50, D-13125 Berlin, Germany.

${ }^{3}$ University Medicine Mannheim, Theodor-Kutzer-Ufer 1-3, D-68167 Mannheim, Ruprecht-Karls-University Heidelberg, Germany.

\begin{abstract}
Background: Formalin is a preservation media for human tissues. Since the chemical structure is known, interaction in tissue preparation can be expected, that affect otoconia morphology. To investigate the suitability of the preservation media using formalin and ethanol for human otoconia in order to prove a shortterm and long-term storage after sampling.

Methods: Intact and degenerate human otoconia samples were exposed to formalin and pure ethanol. Morphological changes were observed by use of environmental scanning electron microscopy (ESEM).

$\underline{\text { Results: }}$ By means of detailed environmental electron microscopy (ESEM) investigations it was shown that formalin is not a suitable storage medium for human otoconia. The solvent of the formalin solution $\left(\mathrm{H}_{2} \mathrm{O}\right)$ attacks the calcite component of human otoconia immediately after exposure. At the same time the organic components of otoconia (proteins) are stabilized by interaction with formaldehyde and their original structure remains unaffected. After ethanol exposure, the morphology of otoconia remains unchanged.

Conclusions: Formalin is not suitable for preservation of tissue material containing otoconia if further ultrastructural and morphological investigations should be performed. A suitable medium for preserving otoconia is pure ethanol, which keeps the composite structure without morphological changes over a long period of time.
\end{abstract}

Keywords: Otoconia, benign paroxysmal positional vertigo, BPPV, otolith organs, saccule, utricle, formalin, ethanol

\section{Introduction}

Investigation of otolith organs has increased considerably during the last years. The examination of morphology and ultrastructure of otoconia is essential to understand physiological processes and pathophysiological mechanisms. Morphological changes and dislocations of otoconia lead to problems in balance and spatial orientation. Otoconia fragments are assumed to cause benign paroxysmal positional vertigo (BPPV), Ménière's disease and vestibular drop attacks [1-3].

Otoconia are generally accepted as being a noncellular component representing the only calcite based biomineral in the human body, whereas bone and teeth are based on calcium phosphate (apatite). The nano-sized calcite component of human otoconia is intergrown with a small amount of organic material $(<5 \%)$ forming the composite structure. Recent studies have revealed the inner structure of human otoconia consisting of a hierarchical architecture with a dumbbell-shaped dense area (branches) surrounded by a less dense, more porous structure (belly) (Figures 1a and 1b) [4-6].

Ultrastructural observations of human otoconia together with common analytical methods is the standard method to provide morphological information [3,7-9]. Preparation and preservation of vital otoconia has been inconsistently reported in literature up to now [7-9]. Recent investigations have shown that the nano-structured inorganic component of otoconia (calcite) is extremely vulnerable to chemical attacks caused by changes in $\mathrm{pH}$ and ionic concentrations as well as by the presence of foreign complexing agents such as gentamicin in the surrounding aqueous medium (endolymph) $[11,12]$. For this reason there is a high risk of destructive interactions during pretreatment and preservation procedures [10]. In general, formalin is used for tissue preservation. In the present study we used vital human otoconia from surgical specimens in order to examine the suitability of the preservation media formalin and 


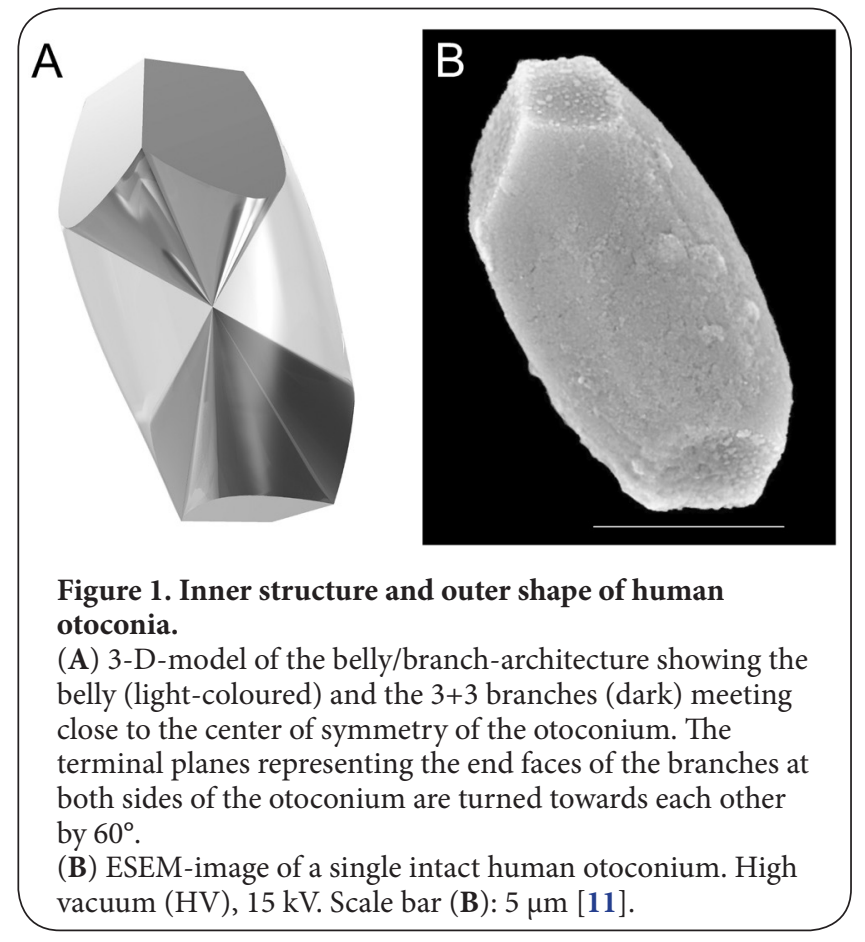

ethanol respectively by an ultrastructural investigation using ESEM at various intervals during the conservation procedures.

\section{Materials and methods}

\section{Otoconia samples}

Vital human otoconia were extracted as described recently [3]. Samples lying in the gelatinous matrix were identified by light microscopy (Axioplan 2 imaging, Carl-Zeiss) with a 300-fold magnification. Parts of the sample were transferred to conductive (polycarbonate/graphite) foil discs (G3347, FEI/Philips) for further investigations by ESEM. Groups of human otoconia were identified at higher ESEM magnifications (>1:10 000) for repeated examination after exposure to the preserving media.

\section{Structural investigation after formalin and ethanol exposure} Experiments were performed by use of commercially available formalin and ethanol. Formalin consists of a 3.5-3.7\% Vol-\% aqueous solution of for maldehyde (methanal) stabilized with methanol to suppress oxidation and polymerization. The measured $\mathrm{pH}$ value (6.88) was close to the neutralpoint (MP220 system, Mettler Toledo, Germany, InLab ${ }^{\circledR} 410$ Combination $\mathrm{pH}$ Electrode).

Ethanol was used in pure grade ( 99.9 Vol-\%, Ethanol 642 MEK abs, Overlack GmbH Mönchengladbach, Germany).

Structural changes of specimens were studied by ESEM before exposure and in time steps up to several hours after exposure by use of uncoated specimens in low vacuum mode $(\mathrm{LV}, 70 \mathrm{~Pa})$. For reproduction of the results experiments were repeated several times. Long-term storage using ethanol was evaluated for a period of up to two years.

\section{Ethics}

The study was conducted in conformity with the declaration of Helsinki 1975, revised in 1983, and approved by the Ethics Committee of the University Medicine Mannheim, University of Heidelberg (2012-612N-MA). Written informed consent was obtained from all participants after the experimental procedure had been explained.

\section{Results}

Dissolution of human otoconia starts immediately after exposure to formalin by producing surface roughening and an increasing number of pores and fissures in the belly region after only 1 hour of exposure. After 3 hours a moderate mass reduction in the belly region is obvious. Progressive mass reduction leads to complete dissolution of the belly until the branch center is reached (after 7 hours). The branches of human otoconia remain stable for a long period of time and outer parts of the branches are still present after 11 hours of formalin exposure. The organic component is not considerable affected during the dissolution process and seems to be stabilized by interaction with formalin. As a result, the outer shape of otoconia is still present even if most of the calcite component is dissolved (Figures 2a-2f).

In the case of ethanol exposure, the morphology of otoconia remains unchanged. Long-term storage in ethanol shows that this also holds true for a period of up to two years (Figures 3a-3f).

\section{Discussion}

The present study clearly reveals that formalin is not suitable for preservation of human otoconia. Formalin is generally used

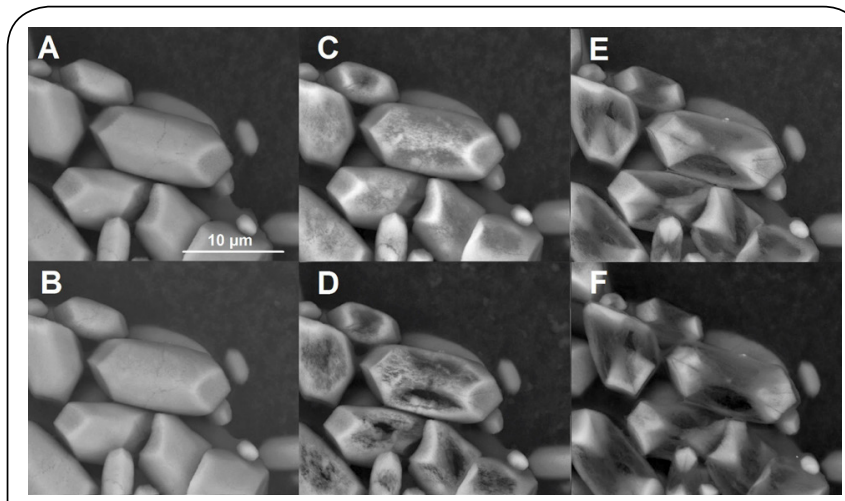

Figure 2. Dissolution sequence of human otoconia during treatment with formalin.

(A) Human otoconia specimen before treatment with formalin. (B-F) Human otoconia after 1,3,5,7,11 hours following exposure to formalin. The chemical attack starts in the belly region by surface roughening and proceeds to center of otoconia. When the center of symmetry of otoconia is reached, residues and fragments as parts of the branches are still present. The organic component of otoconia keeps the shape of the former composite. ESEM, low vacuum (LV), $15 \mathrm{kV}$. Scale bar in $\mathbf{A}(10 \mu \mathrm{m})$ corresponds to $\mathbf{B}-\mathbf{F}$. 


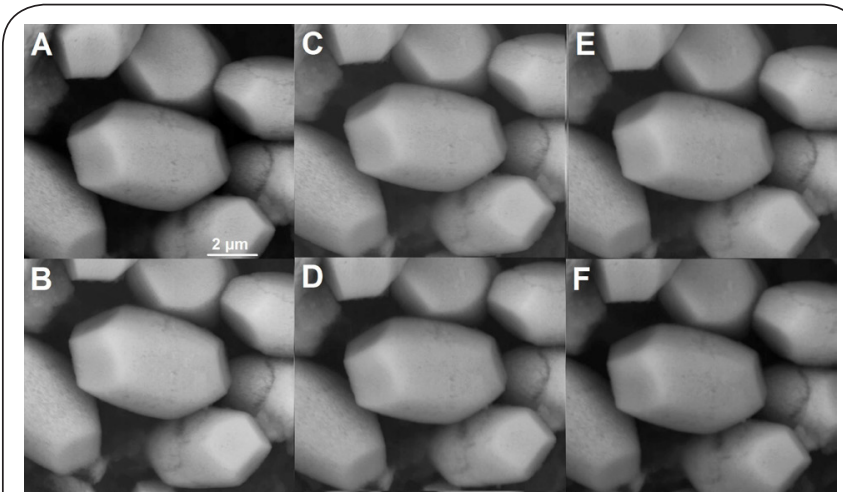

Figure 3. Human otoconia after exposure to ethanol.

(A) Human otoconia before exposure to ethanol.

(B-C) Structural changes after 1, 3, 5, 7, 47 hours following exposure are not obvious. The organic component remains unaffected. The lower brilliance of the images compared with Figure 2 is due to the lack of fixation of the organic part of the composite. ESEM, low vacuum (LV), $15 \mathrm{kV}$. Scale bar in A (2 $\mu \mathrm{m})$ corresponds to $\mathbf{B}-\mathbf{F}$.

for fixing and preserving tissues or cells for pathologic and histologic examination. The organic component of formalin (formaldehyde, IUPAC-name: methanal) causes cross-linking of bio-macromolecular structures. As formalin is based on an aqueous solution of methanal ( $\leftrightarrow$ methandiol) the solvent $\left(\mathrm{H}_{2} \mathrm{O}\right)$ will immediately attack the nano-sized calcite component (>90\% wt.-\%) of otoconia, whereas the protein partial structure $(<5$ wt. $-\%$ of the composite) is fixed and preserved. This scenario is presented in Figures 2a-2f.

The calcite component of otoconia consists of a threedimensional periodic arrangement of calcite nanocrystals showing mismatches (defects and disorder) especially in the belly region, which is the preferred area for chemical attacks and leads to so-called anisotropic dissolution behavior as described only recently [11]. In this case, the belly is dissolved first while the branches are attacked at later stages. The sequences of anisotropic dissolution clearly reveal the hierarchical inner architecture of otoconia consisting of $3+3$ branches and a surrounding belly as shown in Figure 1a $[4-6,11]$.

The disadvantage of destruction of the composite structure by dissolution of the calcite component has to be seen against the advantage of conservation and fixation of the organic (protein) architecture. This is the main reason for the brilliance of the ESEM images (Figures 2a-2f) compared with the quality of images taken after treatment of otoconia with ethanol (Figures 3a-3f).

Some of the images obtained after formalin exposure reveal close structural similarities to degenerate otoconia as described in the literature showing pores and fissures in the belly area as well as fragment formation $[3,7,8]$. Given the results of this study and previous morphological observations, structural changes of otoconia may, in general, be induced within a short period of time during exposure to previously untested chemical agents [9-11,13-14].

In the case of pure ethanol as preserving agent, the lack of structural (morphological) changes clearly reveals that there is no considerable chemical attack on human otoconia for periods of up to several months and years.

Pure ethanol is a suitable storage medium for long-term preservation of human otoconia. The missing presence of methanal, however, causes a lower quality of ESEM images because of the lack of fixation of the organic part of the composite.

\section{Conclusions}

Formalin is not suitable for preservation of the composite structure of human otoconia because of the dissolution of the calcite component by chemical reaction with water (anisotropic dissolution). A suitable medium for long-term preservation of intact and degenerate otoconia is to be found in pure ethanol.

\section{List of abbreviations}

ESEM: Environmental scanning electron microscopy BPPV: Benign paroxysmal positional vertigo

\section{Competing interests}

The authors declare that they have no competing interests.

Authors' contributions

\begin{tabular}{|l|c|c|c|c|}
\hline Authors' contributions & RK & JB & AB & LFW \\
\hline Research concept and design & $\checkmark$ & -- & -- & $\checkmark$ \\
\hline Collection and/or assembly of data & $\checkmark$ & $\checkmark$ & $\checkmark$ & $\checkmark$ \\
\hline Data analysis and interpretation & $\checkmark$ & $\checkmark$ & -- & $\checkmark$ \\
\hline Writing the article & $\checkmark$ & -- & - & $\checkmark$ \\
\hline Critical revision of the article & $\checkmark$ & $\checkmark$ & -- & $\checkmark$ \\
\hline Final approval of article & $\checkmark$ & -- & -- & $\checkmark$ \\
\hline Statistical analysis & $\checkmark$ & -- & -- & $\checkmark$ \\
\hline
\end{tabular}

\section{Publication history}

EIC: Gaetano Giuseppe Magro, University of Catania, Italia. Received: 11-Jul-2015 Final Revised: 27-Aug-2015

Accepted: 31-Aug-2015 Published: 07-Sep-2015

\section{References}

1. Calzada AP, Lopez IA, Ishiyama $G$ and Ishiyama A. Otolithic membrane damage in patients with endolymphatic hydrops and drop attacks. Otol Neurotol. 2012; 33:1593-8. | Article | PubMed

2. Yamane $\mathrm{H}$, Sunami $\mathrm{K}$, Iguchi $\mathrm{H}$, Sakamoto $\mathrm{H}$, Imoto $\mathrm{T}$ and Rask-Andersen $\mathrm{H}$. Assessment of Meniere's disease from a radiological aspect - saccular otoconia as a cause of Meniere's disease? Acta Otolaryngol. 2012; 132:1054-60. | Article | PubMed Abstract | PubMed Full Text

3. Walther LE, Wenzel A, Buder J, Bloching MB, Kniep R and Blodow A. Detection of human utricular otoconia degeneration in vital specimen and implications for benign paroxysmal positional vertigo. Eur Arch Otorhinolaryngol. 2014; 271:3133-8. | Article | PubMed

4. Huang YX, Buder J, Cardoso-Gil R, Prots Y, Carrillo-Cabrera W, Simon P and Kniep R. Shape development and structure of a complex (otoconialike?) calcite-gelatine composite. Angew Chem Int Ed Engl. 2008; 47:8280-4. | Article | PubMed

5. Simon P; Carrillo-Cabrera W, Huang, YX, Buder J, Borrmann H, CardosoGil R, Rosseeva E, Yarin Y, Zahnert T and Kniep R. Structural Relationship 
Kniep et al. Journal of Histology \& Histopathology 2015,

between calcite-gelatine Composites and Biogenic (Human) Otoconia. Eur J Inorg Chem. 2011; 35:5370-7. | Article

6. Walther LE, Blodow A, Bloching MB, Buder J, Carrillo-Cabrera W, Roseeva E, Borrmann $\mathrm{H}$, Simon P and Kniep R. The inner structure of human otoconia. Otol Neurotol. 2014; 35:686-94. | Article I PubMed

7. Ross MD, Peacor D, Johnsson LG and Allard LF. Observations on normal and degenerating human otoconia. Ann Otol Rhinol Laryngol. 1976; 85:310-26. | Article | PubMed

8. Campos A, Canizares FJ, Sanchez-Quevedo MC and Romero PJ. Otoconial degeneration in the aged utricle and saccule. Adv Otorhinolaryngol. 1990; 45:143-53. | PubMed

9. Jang YS, Hwang $\mathrm{CH}$, Shin JY, Bae WY and Kim LS. Age-related changes on the morphology of the otoconia. Laryngoscope. 2006; 116:996-1001. | Article I PubMed

10. Huss D and Dickman JD. Histological preparation of developing vestibular otoconia for scanning electron microscopy. J Neurosci Methods. 2003; 125:129-36. | Article | PubMed

11. Walther LE, Blodow A, Buder J and Kniep R. Principles of calcite dissolution in human and artificial otoconia. PLoS One. 2014; 9:e102516. | Article | PubMed Abstract | PubMed Full Text

12. Walther LE, Wenzel A, Buder J, Blodow A and Kniep R. Gentamicininduced structural damage of human and artificial (biomimetic) otoconia. Acta Otolaryngol. 2014; 134:111-7. | Article | PubMed

13. Serra A and La Mantia I. Normal and altered otoliths of guinea pigs. Scanning electron microscopy observations. Arch Otorhinolaryngol. 1983; 237:209-14. | PubMed

14. Ballarino J, Howland HC, Skinner HC, Brothers EB and Bassett W. Studies of otoconia in the developing chick by polarized light microscopy. Am J Anat. 1985; 174:131-44. | Article | PubMed

\section{Citation:}

Kniep R, Buder J, Blödow A and Walther LE. Destructive properties of formalin on human otoconia. J Histol Histopathol. 2015; 2:19.

http://dx.doi.org/10.7243/2055-091X-2-19 